\title{
Humanistic Studies of Interior Design in New Era
}

\author{
Liu Shaowei \\ Guangdong Vocational College of Hotel Management, Guangdong, Dongguan, 523960
}

Keywords: new era, interior design, humanistic studies

\begin{abstract}
The development of society and the progress of the times make people pay more and more attention to their own development and life enjoyment, as well as humanism, continuously improve their own status, and emphasize the self-awareness and self-personality. The interior design also increasingly tends towards humanistic design, focuses on the feelings and status of people, and is popular with more and more people.
\end{abstract}

\section{Introduction}

With the continuous development of China, respecting people's wishes and values, and emphasizing people's status and feelings have been more integrated into all parts of social production life. As China enters the information age, the emergence of information technology makes people become an important driver of social development, while humanistic feelings and humanistic thoughts gradually evolve into the mainstream of contemporary social development, and are integrated into the interior design of buildings, emphasizing people's enjoyment and experience.

\section{Humanistic Design of Interior Environment of Buildings in New Era}

The interior environment design of the room affects the mood of living and the living experience of the habitant. Interior environment contains rich variety of things, including indoor greening, lighting, color, wall decoration, household, room layout, etc. Various factors mutually coordinate and connect to affect the overall indoor environment settings. To differentiate from the broad aspect, interior environment can be divided into psychological environment, air environment, and space environment. Even if the classification is different, each kind of environment factor is of vital significance to the whole interior environment, and for residents, the design of interior environment will constantly change because of their humanistic feeling and thoughts, however, fixed factors do not change [1].

With the improvement of people's life quality and level, they also have higher requirements for their residential buildings. After the basic living conditions met, they want to have physical and mental, and spiritual enjoyment. In the interior environment design of the room, they do not only pursue living, but comforta, living in comfort.

However, with the deepening and development of science and technology in China, the field of architectural decoration is also gradually casted by science and technology, making the building materials and interior design more humanized and intelligent, which is no longer the previous rigid environmental design, but to make continuous progress and innovation to meet people's increasing demands.

People's demand for the comfort and humanization of interior environment design is the continuous development process of humanistic thoughts and humanistic feelings, which also enables the healthy development and progress of China's construction industry.

The slogan "customer is god" has been gradually popularized in various fields of building materials, making it constantly innovate and reform its own service system to meet the needs of modern people for interior design.

With the development of science and technology and the gradual improvement of human needs, the buildings in China are getting higher and higher, and the interior area is larger and larger. Meanwhile, it is closer and closer. With the continuous development of society, people are too busy 
to appreciate the beautiful scenery of nature in city and are getting further and further away from nature. This also leads to people's yearning for the beautiful scenery of nature in their hearts, hoping to get close contact with the natural scenery [2].

Breaking the boundary between indoor and outdoor and moving the outdoor natural scenery to the indoor environment has become one of the important characteristics of current interior design. A series of elements included in nature and natural scenery are introduced into the interior through certain means and techniques, so that the interior environment is filled with natural elements and elegant demeanor in the design. The natural scenery is displayed in a small corner room to meet people's desire to be close to nature to the maximum extent.

For interior design, sitting room is one of the main design scenario, because the area is large enough, and it has certain level sense and is the core part of interior design. By setting the afforestation, waterscape, as well as decoration and wall murals, the hall design will become a dynamic place of entertainment, giving people a visual enjoyment, and letting them in trouble feel the quiet moment of nature through the interior design serenity [3].

\section{Humanistic Design of Interior Function in New Era}

In the new era, it has realized economic development, scientific and technological progress, while the construction industry has made great progress. After the living conditions of people are basically met, they also put forward requirement for other functions of building. Under the influence of humanistic thoughts and feeling, buildings need not only have the function of basic living and shelter, but also have practical functions. Under the constant change of people's needs, architectural interior design also reforms and changes.

Traditional architecture has a basic living and shelter function, however, with the development of society, the change of the world, the human production and life activities are increasingly rich, which makes buildings not only have the function of living, but also form different architectural interior functions according to the diversity of human activities, as well as the demand of diversity, for the use of human activities. At the same time, the buildings are classified, for example, office building, education teaching building, residential, commercial district, etc., and interior functions also constantly enrich and change with the requirement of human. With humanism, people' life and indoor requirements of architecture are changing as the development of society, and the interior functions will be more and more abundant and diversified accordingly [4].

As people are playing an increasingly important role in society, it causes the development and research of human has been gradually involved in each field in China, which results in more attention to the people of different age, gender and interest and their preference for the interior in the process of building interior design. With humanistic feeling, it gives the unprecedented attention to social vulnerable groups, for example, the building specifically designed for the elderly in China, barrier-free path of city road and so on.

The design of these buildings is becoming more and more standardized and humanized. Considering human factors, it also serves the people in society, so as to promote the construction industry to improve its own competitiveness and develop healthily.

\section{Humanistic Interior Design Related to Spiritual Value in New Era}

In the new era, it encourages freedom and innovation. With humanistic thoughts, human thoughts and themselves are greatly advocated. Under the simulation of science and technology and information in the new era, people's personality and creative ability obtain the unprecedented development. Promoting the individual character and pursuing freedom also makes the construction industry get more inspiration and innovation in the aspect of interior design [5].

With the development and innovation of ideas, more and more novel materials and decoration design techniques and means have emerged in the field of building materials, which has laid a good technical foundation for personalized and innovative interior design.

According to the different needs of different people for interior design, people can show their 
distinctive personalities and preferences in interior design, so as to gradually promote the development of architectural interior design.

Different from that of the whole building, once the building is completed and put into use, the life for the building will be decades or even hundreds of years unless the damage by natural disasters and force majeure; however, architectural interior design is different, and its periodicity and existence time is short and will change according to the different needs of residents and people, the change of thought and humanities, then it causes the original interior design is not in conformity with the requirements, but to be replaced, to conform to the present social development trend, and modern people's aesthetic view.

In the new era, the society changes with each passing day, and even is different every day. The update and change of interior design also makes the periodicity is increasingly shorter. According to the author's survey, for commercial buildings such as hotel, the guest room's interior design needs to be replaced once every three years, to ensure that residents feel fresh, and also conform to the present people's aesthetic and requirements. For the commercial building front, the design needs to be updated once every 1 to 2 years, to ensure freshness and attract different customers.

Interior design is influenced by external factors to a large extent; the development of the times, the change of the theme, the change of the cultural ideological trend, the public's preferences and preference will affect the change of interior design. From the aspect of internal users and residents, their emotion, preference change can cause interior design is faced with update and change, and the rapid change of interior design puts forward higher request for relevant personnel. Only by constantly grasping the trend of social development can it satisfy the demand of users and residents at the time of indoor design, to cater to the tastes of the times, and make its design keep longer [6].

\section{Pursuit of Healthy Factor of Interior Design in New Era}

The development of the times and social progress makes people in new era set off an upsurge "health". Health maintenance is no longer limited to the middle-aged and old people, and even post-90s and post-00s all start taking the route of health maintenance. It is not just a social progress of thought, and at the same time, it is the development of humanistic thought under the influence of humanism. For the people in China, house is the place where they stay the longest, so interior design must be healthy with environmental protection, in order to ensure their health, in line with the current upsurge of health preservation.

Green environmental protection, energy conservation and emission reduction, formaldehyde-free pollution, have become the current architectural decoration and the most popular phrase of interior design, as a result, people's requirement for indoor building gradually changes along with the development of the era; the comfort and beauty of interior design is the key, and health preservation is priority among priorities. Therefore, in indoor design, people pay more attention to the material, and need to adopt the formaldehyde-free, non-radiation, purely green, pollution-free environmental protection material, in order to accord with the requirement of people for interior design. Health and health preservation have become another hot spot of interior design in the new era.

For the color of interior design, people also gradually start to attach importance to it. Color is no longer just a simple color but affects the mood and inner heart of people. Good color collocation helps to regulate people's psychology and form healthy and positive personality; on the other hand, it will bring bad influence [7].

For example, pink and purple are used to decorate indoor wall and the whole. If it is used for long time, it can bring about depressed disease and melancholia. However, orange red color has stimulation on people's brain nerve, stimulating appetite.

\section{Conclusion}

In the new era, ideological trend of humanism is more popular, and people also pay more attention to their own needs and enjoyment in the development of the society. The interior design as the concerns of the people should fully understand the humanism, focus on the preferences of users 
and habitants, understand the current social trends, so as to promote the healthy development of interior design.

\section{References}

[1] He Hinming. Research on the integration of architectural interior design and overall architectural design. Jiangxi building materials, 2017(21):57+61.

[2] Zhao Chunguang. Research on the application of humanistic aesthetics in Chinese architectural interior. Interior Architecture of China, 2016(07):124-125.

[3] Wu Meifang. Analysis of humanistic complex in modern interior design. Shanxi architecture, 2003(11):1-2.

[4] Yang Xudong. Analysis of humanistic interest in interior environmental art design. Contemporary education practice and teaching research, 2018(05):240-241.

[5] Li Tao. Relationship between interior space division and people. Shanxi architecture, 2013, 39(04):9-11.

[6] Jiang Hui. Research on interior design based on human factors. Journal of Nanjing institute of industry technology, 2006(03):32-33+60.

[7] Wang Li. Role of indoor natural landscape design. Tropical forestry, 2007(02):18-21. 